\title{
GESTÃO PARTICIPATIVA: A PRÁTICA EM UMA GRANDE SIDERÚRGICA
}

PARTICIPATIVE MANAGEMENT: PRACTICE IN A BIG STEEL COMPANY

Recebido em 21.02.2018. Aprovado em 04.06.2018

Avaliado pelo sistema double blind review

DOI: http://dx.doi.org/10.12712/rpca.v12i2.1081

\section{Elisângela Domigues Michelatto Natt}

Universidade do Vale do Itajaí (UNIVALI), Itajaí/SC, BRASIL

elisdomingues@gmail.com

\section{Paula Fernandes Furbino Bretas}

Universidade Federal de Minas Gerais (UFMG), BELO HORIZONTE/MG, BRASIL

paulaffb@gmail.com

\section{Marcos Moura-Paula}

Instituto Federal de Brasília (IFB), Brasília/DF, BRASIL

marcos.moura@ifb.edu.br

\section{Alexandre de Pádua Carrieri}

Universidade Federal de Minas Gerais (UFMG), BELO HORIZONTE/MG, BRASIL

aguiar.paduacarrieri@terra.com.br

\section{Resumo}

Nosso objetivo foi compreender como as práticas de gestão participativa (GP) foram desenvolvidas em uma empresa siderúrgica considerando como agente e estrutura se constroem mutuamente numa perspectiva bourdieana. Fizemos entrevistas não estruturadas com trabalhadores da empresa e com sindicalistas e as analisamos com base na Teoria de Campos. Observamos que mesma estrutura que delimita as ações também proporciona resistências e incorporações, num processo conturbado, mas passível de acomodações e transições, idas e vindas, que requerem a prática dos agentes para alimentarem o campo a partir das capacidades inventivas e dóxicas que valorizam agência e estrutura, simultaneamente, ora privilegiando uma, ora, a outra. A análise nos permitiu perceber que as práticas de GP permitiram que houvesse tanto avanços quanto permanências de relações de dominação nas relações de trabalho e gestão de pessoas.

Palavras-chave: Agente-Estrutura. Gestão Participativa. Teoria dos Campos.

\begin{abstract}
Our aim was to understand how practices of participative management (PM) were developed into a steel company taking into account how agent and structure build one another in a Bourdieusian perspective. To achieve this goal, we carried on unstructured interviews with company employees and trade union members, analyzing them based on the Theory of Fields. We noted that the same structure that narrows actions also provides resistances and mergers, in a troubled process, but subjected to accommodation and transitions back and forth, which requires practices of the agents to feed the field from their inventive and doxic capabilities that value both agent and structure simultaneously, sometimes flavoring the latter, sometimes the former. The analysis allowed us to realize how the PM practices allowed both developments and permanence of relations of domination in Labor Relations and Human Resources Management.
\end{abstract}

Keywords: Agent-structure. Participative Management. Theory of Fields. 


\section{Introdução}

A gestão participativa (GP) é um dos conceitos centrais na literatura de gestão, embora sem uma conceituação clara do que seja participar (KAUFMAN, 2001). Alguns pesquisadores (FURTADO, 2008; SILVEIRA; OLIVEIRA; PALASSI, 2012) observam que há duas linhas principais da pesquisa sobre a temática. Uma linha considera que a participação nas empresas não deixaria de ser apenas mais uma roupagem para manipular e dominar os trabalhadores, já a segunda linha considera que a participação traz vantagens tanto para os trabalhadores quanto para os empregadores. Furtado (2008) observa ainda que muitas vezes os pesquisadores fazem dicotomias entre macro e micro, agente e estrutura, que levariam a perder de vista as interações entre esses polos.

Assim, a autora buscou compreender a GP a partir da relação agente e estrutura, tentando superar a dicotomia entre o nível micro (Gestão de Pessoas) e macro (Relações de Trabalho) de análise (FURTADO, 2008). Para Furtado (2008), apoiada na Teoria da Estruração (GIDDENS, 1989), é necessário pensar a GP dentro da lógica das relações de trabalho, na qual agente e estrutura são vistos em interação contínua. Nosso objetivo aqui é fazer um movimento tanto semelhante quanto distinto daquele feito por Furtado (2008). Semelhante à medida que consideramos que não devemos reproduzir a ênfase em um dos polos (agência ou estrutura) em detrimento do outro como se houvesse superioridade entre eles. Distinto à medida que recorremos à praxeologia bourdieana em detrimento da Teoria da Estruturação, que considera que os agentes atuam em uma situação ideal, "não constituída a partir de interesses" (MISOCZKY, 2003, p. 11).

Segundo Misoczky (2003, p. 11), Giddens "incorpora a concepção parsoniana do poder como a capacidade de atingir resultados, como meio, ignorando que a obtenção de recursos de poder pode ser também um fim". Questão essa não ignorada por Bourdieu ao compreender que os agentes possuem diferentes capitais que lhes legam diferentes posições nos campos sociais. Bourdieu permite dar continuidade à discussão epistemológica trazida por Furtado (2008) na GP, sem abrir mão da pesquisa empírica, considerada de grande relevância pelo autor francês (EVERETT, 2002). Ao buscarmos compreender a prática da GP em uma siderúrgica, a articulação dos conceitos fundamentais de campo, capital e babitus (SWARTZ, 2008), que só são plenamente entendidos de forma relacional (RIVERA; BRITO, 2015), mostrou-se bastante profícua nesse intento.

Dessa forma, nosso objetivo foi compreender como as práticas de GP se desenvolveram em uma empresa siderúrgica considerando como agente e estrutura se constroem mutuamente. Assim, tentamos evitar dar demasiado peso a um dos polos dessa relação, tentando superar as análises que dicotomizam agente e estrutura, objetivismo e subjetivismo, níveis macro e micro (CARVALHO NETO, 2012; FURTADO, 2008). Consideramos que há um espaço de construções que remete à estrutura, mas também a capacidade inventiva dos indivíduos, entendidos aqui como agentes. Baseando-nos em Bourdieu (2004; 2008a; 2008b; 2008c; 2009a; 2009b; $2009 \mathrm{c}$ ), entendemos que as estruturas existem e, de alguma forma, envolvem as práticas dos agentes, que podem reproduzir ou subverter as regras em campo, de forma que as ações são impulsionadas pela estrutura, seja para a manutenção ou subversão.

Para Bourdieu (2008a, 2008b, 2009c), a mesma estrutura que possibilita a reprodução de normas e regras, também permite a mudança. Tanto as mudanças quanto às acomodações e manutenções na estrutura de poder são respostas às pressões do jogo. Sendo que o mais importante é considerar que há uma interação constante do agente no campo. O agente pensa, é inventivo, cria, interpreta e subverte ou, ainda, pode apenas manter a ordem estabelecida, mas há o momento de decisão, de elaboração e de resposta, seja ela qual for. É nesse meio, da complexa teia estrutural, que se torna difícil a separação entre agente e estrutura.

Considerando esses aspectos investigamos a história da empresa e buscamos conhecer algumas das práticas dos agentes em torno dos motivos que levaram à adoção, por parte dos gerentes, do trabalho em equipe como um instrumento fixador de regras e valores. Como eram implantadas as práticas de gestão e como o trabalho em equipe era valorizado. Havia, de fato, um trabalho em equipe? Mediante tais questionamentos, entendemos que seria necessário um olhar sobre os ganhos ou perdas simbólicos, a partir da perspectiva dos agentes, sem isolá-los da estrutura, mas compreendendo a interação inevitável entre ambos. Para isso, entrevistamos gerentes e não gerentes, representantes do sindicato da área e da associação de aposentados e analisamos todo o material resultante desse processo sob a perspectiva qualitativa.

Além desta introdução, este trabalho possui mais cinco seções. A seguir, fazemos uma breve revisão dos estudos sobre GP. Na seção seguinte, apresentamos a Teoria de Campos de Bourdieu e sua relevância para os estudos em administração. $\mathrm{Na}$ quarta seção, caracterizamos a empresa pesquisa e a metodologia que utilizamos. Na quinta, analisamos nossos dados. Na sexta, por fim, apresentamos as considerações finais. 


\section{Gestão Participativa}

A participação ou gestão participativa (GP) é um conceito clássico na literatura de gestão que remete aos anos 1930 (PARDO-DEL-VAL; MARTÍNEZ-FUENTES; ROIGDOBÓN, 2012). Kaufman (2001) mostra como os estudos sobre GP foram desenvolvidos paralelamente aos sobre gestão estratégica de recursos humanos nos Estados Unidos desde o começo do século XX. Não há, contudo, um conceito único ou claro de GP (PATRUS et al., 2012; SILVEIRA et al., 2012). Sintetizando o pensamento de vários pesquisadores, Pardo-del-Val et al. (2012) indicam que a GP se refere ao envolvimento na tomada de decisões de modo que todos os membros da organização pensem de modo estratégico e aceitem a plena responsabilidade de seu trabalho, não deixando de focar na satisfação dos clientes e bom funcionamento da organização. Acrescentese ainda que a participação aumenta o comprometimento dos trabalhadores e diminui sua resistência à mudança organizacional (PARDO-DEL-VAL et al., 2012), além de promover o consenso e a cooperação, otimizando a produtividade, a qualidade e a eficácia organizacionais (NOGUEIRA; BIZARRIA; TASSIGNY, 2014).

Além desses pontos positivos trazidos pelos pesquisadores, é importante saber como as pesquisas sobre GP têm sido desenvolvidas no Brasil. Segundo Silveira et al. (2012) existem duas linhas de interpretação distintas: aquela que defende a GP como mais uma forma de manipulação e dominação e aquela que acredita que empregados e empregadores podem ter vantagens com a GP. Buscaremos contextualizar esses estudos brevemente. Antes, porém, faremos uma tentativa de delimitação conceitual.

De forma geral, Faria (2009) relaciona a participação com proximidade ao poder e define três níveis de controle (econômico,político-ideológico epsicossocial) queinfluenciam nos modos de gestão. Estes modos muitas vezes são usados como sinônimos, o que o autor critica. Ele argumenta que os diferentes níveis de controle caracterizam a experiência alemã de cogestão, a experiência iugoslava de cooperativas de produtores associados, a experiência brasileira das comissões de fábrica, a experiência dos kibutzim, a experiência das cooperativas tradicionais (ou gestão cooperativa limitada pelo seu caráter empresarial no Brasil), a Economia Solidária, entre outras, e todas elas guardam convergências e divergências entre si (FARIA, 2009).

Apesar da pluralidade do que se entende por GP, o foco deste artigo recairá sobre a perspectiva gerencialista, no âmbito das práticas participativas fomentadas na heterogestão. No final da década de 1970, a temática da participação era difundida como algo positivo. As divulgações da imprensa sindical e também da imprensa empresarial associavam a GP a uma oportunidade para que os trabalhadores pudessem alcançar os sistemas de gestão de forma mais colaborativa. Especificamente do ponto de vista dos profissionais, o mais importante era a implantação de comissões de fábrica, associada à estabilidade. No Brasil, um exemplo foram os projetos implantados nas empresas do ABC paulista. Já para os empresários, as comissões dos representantes eleitos pelos trabalhadores nas empresas eram uma forma de criar possibilidades para a solução de problemas no interior das organizações, evitando movimentos indesejáveis, como as greves. Nesse sentido, percebe-se que os anos 1970 constituíram um período em que o maior objetivo nas organizações não era o aumento da produtividade, mas impossibilitar o surgimento e estabelecimento de conflitos (DONADONE, 2002).

Kochan e Osterman (1994), estudando o sistema alemão na perspectiva das Relações de Trabalho, observaram que a prática dos conselhos oferecia uma melhor possibilidade para a participação nos processos de tomada de decisão, pois acabava oferecendo algumas possibilidades de superação das dificuldades encontradas nos processos de negociação coletiva tradicionais. Mesmo fazendo parte das Relações de Trabalho como um todo, é importante salientar as diferenças existentes dos estudos no contexto brasileiro e europeu. Enquanto os processos de negociação coletiva nos Estados Unidos e Europa eram desenvolvidos desde o início do século XX, pois havia uma classe de trabalhadores industriais urbanos amadurecida e, portanto, possuíam sindicatos combatentes, no Brasil, há de se pontuar o pouco amadurecimento dessa classe e o contexto da ditadura na década de 1970 no qual os sindicatos foram sendo cada vez mais enfraquecidos em função de um controle maior por parte do Estado (GIL, 2007).

Resguardadas essas diferenças, Heckscher (1996) e Zibas (1997) consideram como consequência sobre as relações sindicais o enfraquecimento gradativo da mobilização. Esse fenômeno se caracterizou, primordialmente, porque os sindicatos ainda funcionavam de acordo com a lógica taylorista, com linhas divisórias claras entre trabalhadores e gerentes (PIORE, 1991; HECKSCHER, 1996; LOCKE, 1999). Heckscher (1996) aponta que, mesmo em casos como os apresentados por Kochan e Osterman (1994), as propostas mais ousadas ainda esbarravam nas decisões dos gerentes. Ainda assim defendem que é possível que em programas de cooperação nos níveis operacionais mais baixos as relações possam ser melhoradas a fim de se estabelecer alguma comunicação de mão dupla entre chefes e subordinados, influenciando os processos de estabelecimento de normas e outras questões mais significativas. 
Já na década de 1980, o modelo japonês ultrapassou as fronteiras geográficas e foi disseminado em vários países, incluindo nessa lista o Brasil. A partir de então, foram vários os grupos que se destacaram por trabalhar a GP, fosse como grupo que privilegiava o processo de soluções de problemas ou como grupos semiautônomos como os Círculos de Controle da Qualidade (CCQ). Esse segundo formato agregava grupos de operários formados nos locais de trabalho, mas paralelos à organização formal. O objetivo era promover a discussão e apresentação de ideias para a solução de problemas nos processos de trabalho (HECKSCHER, 1996; TOLFO; PICCININI; GUIMARÃES, 1999).

Segundo Locke (1999), esses grupos proporcionaram uma valorização da flexibilidade na organização do trabalho, tornando-a um elemento crítico para que a capacidade competitiva das empresas pudesse ser garantida. Nesse sentido, formas alternativas de organização foram desenvolvidas, como os instrumentos da Qualidade Total, os CCQs e os grupos de trabalho em equipe. Vale ressaltar que tais movimentos surgiram em todas as economias industriais avançadas, o que pode ter sido uma espécie de resposta à crise do capitalismo enquanto modo de produção, que não apenas tornou emergente a necessidade de novas formas de gestão, como também culminou num processo de desenvolvimento de novas políticas para a área de recursos humanos. Todo esse movimento foi perpassado por constantes tentativas para envolver e comprometer o trabalhador, conforme os objetivos da empresa, induzindo-o a assumir responsabilidades e participar mais do processo, sendo proativo e aprendendo a trabalhar em equipe (TOLFO; PICCININI; GUIMARÃES, 1999).

Conforme Pardo-del-Val et al. (2012), a GP pode aumentar a colaboração entre os trabalhadores, fazendo com que eles ajudem na tomada de decisões. Esses autores, todavia, apontam que as decisões podem ser em nível operacional, tático ou estratégico; havendo assim, embora os autores evitem tratar da questão, assimetrias de poder, como apontado por Tragtenberg (1980). Segundo este autor, ao analisar os sistemas de participação, as decisões mais importantes nos processos gerenciais são definidas pelos representantes dos acionistas e representam exclusivamente os interesses das empresas, enquanto apenas um representante dos trabalhadores está presente nos trabalhos da diretoria, o que configura a desigualdade no processo, inviabilizando uma influência significativa, por parte dos funcionários, nos processos de decisão.

Para Faria (2009, p. 99), nos sistemas heterogeridos, "a organização do trabalho responde sempre a uma necessidade econômica, que é a de obter a maior produtividade possível, e a uma necessidade político-ideológica, que é a de manter o conjunto dos produtores subordinados ao capital". Portanto, os produtores possuem um nível de controle, mas sempre restrito ao nível do processo imediato de trabalho. Além disso, esses sistemas aparecem "como uma forma sofisticada de heterogestão e não como uma forma de gestão participativa caracterizada como os comitês ou conselhos de fábrica, enquanto resultado do conflito de classes ou de segmentos de classe social" (FARIA, 2009, p. 100). Assim, não por acaso, Pardo-del-Val et al. (2012) alertam que um estilo de gestão mais participativo não prescinde de uma supervisão inicial que organize, eduque e guie os funcionários.

Corroboramos com Carvalho Neto (2012), sobre a necessidade de discussão epistemológica que permeiam estudos na área de Relações de Trabalho, identificado por ele como o macro, e na área de Gestão de Pessoas, identificado como o micro. Contudo, na tentativa de ampliar o debate, pretendemos sair dessa dicotomia entre macro e micro, demonstrando que temáticas das duas áreas não possuem uma fronteira tão rígida. Argumentamos que relações sindicais e de negociação, por exemplo, foram e continuam sendo influenciadas por práticas da gestão (e da gestão de pessoas), como a GP e os mecanismos sutis desenvolvidos para envolvimento dos trabalhadores para com a organização. E a recíproca é verdadeira, pois as práticas de gestão (e de gestão de pessoas) também influenciam o desenvolvimento das relações sindicais e de negociação, seja para fortalecimento (em menor escala) ou enfraquecimento dos sindicatos.

Enquanto Carvalho Neto (2012) situa a Escola de Frankfurt entre dois extremos, representados pelo marxismo e pelo positivismo, acreditamos que há possibilidades de filiação a uma epistemologia como o marxismo, sem necessariamente cair em todas as polarizações criticadas pelo autor (subjetivismo versus objetivismo, irracionalismo versus racionalismo, ação do indivíduo versus estrutura, volição do indivíduo versus não volição, contexto condicionante versus contexto determinante). Entendendo a epistemologia como um modo de produção do conhecimento imerso em um ambiente de disputa de poder, encontrar meios-termos seria como minimizar o conflito e maximizar o consenso, o que enfraquece a luta das minorias, mesmo na ciência. Por isso, desenvolveremos o argumento da não dicotomia entre agência-estrutura a partir de um conhecimento epistemologicamente delineado nos tópicos seguintes, com o aporte teórico de bourdieano. 


\section{Teoria dos Campos}

De formação em filosofia, mas intrigado com os movimentos e as organizações humanas, Bourdieu trabalhou por cerca de 40 anos com diversas questões sociais, tais como a educação, a política e a própria sociologia. Nesse percurso, entre tantos avanços e perspectivas lançados pelo autor, destacamos sua constante preocupação com as relações de dominação e a formulação da Teoria dos Campos. Bourdieu (2004; 2008a; 2008b; 2008c; 2009a; 2009b; 2009c) analisou várias circunstâncias da vida social, como as práticas escolares, as profissões, as relações de gênero, as religiões, o mundo acadêmico, a comunicação, dentre outros temas. Ao lançar sua perspectiva teórica, o autor considerou que as relações e as práticas dos sujeitos só podem ser compreendidas a partir do contexto e das condições de possibilidades.

Bourdieu (2009c) não abriu mão das estruturas sociais em seus trabalhos. Partiu da perspectiva de Levi-Strauss sobre o estruturalismo clássico, mas avançou ao buscar compreender as condições materiais de produção simbólica, fundando o que ele chamou de estruturalismo genético. Bourdieu definiu como campo as estruturas sociais objetivas e como habitus as estruturas incorporadas (MISOCZKY, 2003). "Os campos são como microcosmos sociais que possuem objetos e interesses específicos, denominados capitais, que são tanto instrumentos quanto objetos de disputa" (SOUZA FILHO et al., 2013, p. 673). Já o habitus está relacionado a "esquemas simbólicos subjetivamente internalizados de geração e organização da atividade prática dos agentes individuais, esquemas que tomam a forma de disposições mentais e corporais", ou seja, "modos potenciais socialmente adquiridos e tacitamente ativados de agir, pensar, sentir, perceber, interpretar, classificar e avaliar" (PETERS, 2013, p. 48).

Bourdieu (2009b) não nega que as práticas dos agentes estejam imbricadas nas posições ocupadas por eles no campo, mas nesse espaço de forças e lutas, as regras podem ser acomodadas ou subvertidas. Os agentes são capazes de, a partir das disposições adquiridas e do babitus, se reinventarem e manterem alguma autonomia, o que dependerá dos capitais distribuídos no campo, das regras estabelecidas para o jogo e da distância em relação ao núcleo de poder do campo (Bourdieu, 2004). Para Bourdieu (2009a), as relações de poder perpassam um campo e distribuem os agentes conforme os capitais valorizados no jogo. Os capitais possíveis são multiformes, podendo estar na forma do capital econômico, do capital cultural, do capital linguístico, do capital social e do capital político (EVERET'T, 2002). Entretanto, o capital valorizado em determinado campo é chamado de capital simbólico, constituído a partir da síntese dos outros capitais na medida em que estes são conhecidos e reconhecidos devido a sua respectiva importância no campo (SOUZA FILHO et al., 2013).

Os capitais e os habitus podem ser adquiridos pelos agentes em mais de um campo, simultaneamente, mas o aproveitamento dos capitais dependerá da recepção e valorização no campo onde serão utilizados. São os capitais que dão o suporte necessário para que cada agente reaja à pressão da estrutura, que será proporcional à sua fragilidade no campo. A força ou fragilidade dos capitais que dispõem em relação ao campo, orientará o agente para a mudança ou estagnação de sua posição no campo, conforme os sistemas temporários de possibilidades no campo (BOURDIEU, 2004).

Além disso, é no interior de cada campo que as relações objetivas são delineadas e as estratégias de manutenção ou subversão articuladas. Sobre essas relações objetivas e as permutas manifestas na estrutura, é importante lembrar que os vários campos que impactam na constituição de cada agente são também hierarquizados, influenciando em outros campos conforme o privilégio de sua posição em relação aos demais. Um mesmo ambiente ou tema considerado como um campo pode ser considerado um agente, dependendo do recorte dado pelo pesquisador. Outro aspecto importante é que a vontade de um indivíduo não é por si só a razão de ser de um campo, pois é preciso que essas vontades corroborem ou coadunem outras vontades e, numa coalizão, interfira no jogo em maior ou menor grau (BOURDIEU, 2004). Para melhor compreender essa dinâmica, não se pode esquecer, de forma alguma, que os campos são recortes conceituais, desenhados a partir das relações de poder observadas em determinadas circunstâncias ou a partir de determinados temas. Os agentes não estão confinados a um campo, aliás, podem transitar por vários campos ao mesmo tempo ou ao longo de suas vidas, mas pode haver um campo específico que impacte mais suas histórias de vida. Segundo Bourdieu (2008a), as instituições escolares são os caminhos mais comuns na atualidade para manter ou possibilitar mudanças relativas às posições no campo.

Sob essa perspectiva, embora a estrutura delineie as práticas dos sujeitos, ela não as determina. Pode parecer sutil a diferença, mas ela é significativa, já que nesse caso as práticas ganham forma a partir da perspectiva e elaboração dos agentes. A estrutura, portanto, é criada e reproduzida pelo homem nas mais variadas formas de organização social, impacta as ações $\mathrm{e}$ as decisões individuais e coletivas, orientando-as, mas sem predeterminá-las. Já os agentes, dotados de capacidades inventivas, podem aceitar 
reproduzir ou, ainda, subverter e resistir. As resistências possíveis não modificam radicalmente a estrutura ou mesmo as desconstroem, mas podem promover pequenas revoluções e, num longo período histórico promover o estabelecimento de novas formas estruturais, sendo comum pensar que a estrutura é estática mesmo não sendo (BOURDIEU, 2008a; 2009a).

Apesar de darmos ênfase aos conceitos considerados fundamentais de campo, habitus e capital (SWARTZ, 2008), é importante salientar que a proposta analítica de Bourdieu (2009a) também considera os conceitos de doxa, nomos, illusio. A doxa está ligada a um senso de consenso, que dissimula para possibilitar as relações de dominação, estimulando os agentes a concorrer ou colaborar, promovendo, a partir dos interesses específicos, uma naturalização das forças (BOURDIEU, 2009a), representando, assim, o senso comum (Souza Filho et al., 2013). O nomos, por sua vez, reúne as leis gerais, invariantes, de funcionamento do campo, pois "todo campo, como produto histórico, tem um nomos distinto" (THIRY-CHERQUES, 2006, p. 37). Doxa e nomos são legitimados no e pelo meio social inerente ao campo (THIRY-CHERQUES, 2006). Já a illusio seria o investimento que faz um jogador acreditar que o jogo vale a pena ser jogado, conferindo um sentimento de pertença ao campo.

É por meio da noção de illusio que se explica o convívio entre as diversas classes sociais, unificadas em uma mesma estrutura de sentido que possibilita a realização da prática. Pois ela amansa os dominados possibilitando o consenso sobre as regras do jogo, de forma que a doxa seja imposta por um poder simbólico, ou seja, por um poder invisível capaz de impor significações legitimadas. Um poder de constituir a realidade a partir de um enunciado que se faz valer pela mobilização, mais do que pela força (RIVERA; BRITO, 2015, p. 564).

Diante do exposto, a praxeologia bourdieana nos permite estudar as práticas de GP, considerando tanto aspectos subjetivos quanto os objetivos envolvidos nesse processo. Além disso, o aporte teórico provido por Bourdieu nos permite também analisar as relações de poder e as diferentes posições ocupadas pelos agentes no campo conforme os capitais de que cada um dispõe. A seguir apresentamos a caracterização da empresa e o método de pesquisa utilizado.

\section{Caracterização da Empresa Pesquisada e o Caminho Percorrido}

Para realização desta pesquisa, recorremos à investigação documental e à realização de entrevistas. Nosso trabalho foi realizado em uma empresa siderúrgica de grande porte. Sua constituição jurídica inicial era de capital misto, mas atualmente a empresa é uma sociedade de capital aberto. Quando começou operar, as ações da empresa eram divididas entre o governo do Estado de Minas Gerais, o Governo Federal e empresas japonesas.

Com a ditadura no Brasil, a Empresa S. passou a responder a holding Siderbrás. Já durante o governo do presidente Fernando Collor, no ano de 1991, foi privatizada. Ao longo de sua existência a empresa original ganhou novos contornos, adquiriu outras plantas e expandiu seus negócios e sua capacidade produtiva. A realização desta pesquisa, todavia, ocorreu apenas com os empregados da planta original, instalada na região metropolitana de Belo Horizonte, no estado de Minas Gerais.

Essa primeira unidade industrial, cujas operações tiveram início na década de 1960, hoje funciona como a matriz da organização. Nos últimos anos a empresa tem produzido laminados a frio e a quente e sua capacidade produtiva é de 9,5 milhões de toneladas por ano. Feitas essas observações, informamos que este artigo faz parte de uma pesquisa maior que começou com algumas visitas à empresa, onde se realizou a coleta do material de comunicação produzido pela Empresa S. a partir da década de 1960 e foram feitos alguns contatos que deram origem a uma série de entrevistas individuais em profundidade não estruturadas (MATTOS, 2006).

Foram feitas oito entrevistas, cujos participantes, em sua maior parte, ocuparam algum cargo de gestão ao longo de suas carreiras na empresa, mais especificamente no período em que a empresa apresentava uma estrutura cuja hierarquia era mais definida, entre as décadas de 1960 e 1990, e estavam aposentados. Entre os entrevistados, estava também o presidente do sindicato dos trabalhadores ativos. O Quadro 1 ilustra uma breve descrição dos entrevistados.

Quadro 1. Descrição dos Entrevistados

\begin{tabular}{|l|l|l|l|}
\hline Participante & Cargo ocupado & $\begin{array}{l}\text { Entrada } \\
\text { na } \\
\text { Empresa } \\
\text { S. }\end{array}$ & $\begin{array}{l}\text { Situação na } \\
\text { época da } \\
\text { entrevista }\end{array}$ \\
\hline Entrevistado 1 & $\begin{array}{l}\text { Superintendente } \\
\text { de Engenharia }\end{array}$ & 1960 & Aposentado \\
\hline
\end{tabular}




\begin{tabular}{|l|l|l|l|}
\hline Entrevistado 2 & $\begin{array}{l}\text { Superintendente } \\
\text { de Informática }\end{array}$ & 1964 & Aposentado \\
\hline Entrevistado 3 & $\begin{array}{l}\text { Chefe de } \\
\text { Departamento }\end{array}$ & 1975 & Aposentado \\
\hline Entrevistado 4 & Chefe de Divisão & 1970 & Trabalhando \\
\hline Entrevistado 5 & $\begin{array}{l}\text { Gerente de } \\
\text { Remuneração e } \\
\text { Benefícios }\end{array}$ & 1973 & $\begin{array}{l}\text { Demitido em } \\
2009\end{array}$ \\
\hline Entrevistado 6 & Chefe de Divisão & 1959 & $\begin{array}{l}\text { Aposentado } \\
\text { em 1984 }\end{array}$ \\
\hline Entrevistado 7 & $\begin{array}{l}\text { Analista de } \\
\text { Recursos } \\
\text { Humanos }\end{array}$ & 1976 & Aposentado \\
\hline Entrevistado 8 & $\begin{array}{l}\text { Fiscal de Obras/ } \\
\text { Presidente do } \\
\text { Sindicato }\end{array}$ & 1978 & Licenciado \\
\hline
\end{tabular}

Fonte: Dados de pesquisa

Para a análise do material coletado recorremos à Teoria dos Campos de Bourdieu, cujo corpus nos permite tanto um arcabouço teórico quanto analítico, pois pode ser considerada teoria e método. Para Kozick et al. (2013) o método de Bourdieu junta teoria e prática e discute o papel do pesquisador e sua influência para a pesquisa, apresentando novos parâmetros para a investigação social. Isso nos permite um alcance profundo sobre as relações que perpassam a vida organizada, já que abre caminho para investigações abrangentes em campos variados. Esse aspecto é importante porque permite que o pesquisador exerça seu papel na sociedade destruindo as prenoções e o senso comum, elaborando novas maneiras para alcançar alguma compreensão sobre as instituições, as relações de poder e os modos de vida.

Bourdieu defendeu a busca por um conhecimento sem doutrinas, sem amarras intelectuais ou fórmulas elaboradas apriori. Ao apontar a possibilidade de mudança nas estruturas de poder a partir das pressões coletivas, Bourdieu propôs que caberia ao pesquisador combater a naturalização e o fatalismo do mundo socialmente constituído, promovendo o desvelamento das causas objetivas e das razões subjetivas que impactam os agentes (SCARTEZINI, 2011).

A partir desse posicionamento, e tendo apresentado nossos apontamentos sobre a abordagem, a coleta de informações e o tratamento do conteúdo obtido durante a realização da pesquisa, desenvolvemos a seguir nossas análises, bem como ilustramos alguns trechos dos materiais coletados que permitirão como aspectos objetivos e subjetivos estão imbricados nas práticas desenvolvidas de GP na Empresa S.

\section{O Jogo da Gestão Participativa na Empresa S.}

Ao considerar a Empresa S. como um campo, admitimos que ela representa um espaço simbólico de lutas e de forças, cujos agentes recorrem aos capitais de que dispõem para se posicionar perante a estrutura, sendo impactados por ela e, ao mesmo tempo produzindo efeitos no campo. Buscamos entender os discursos (como prática) a partir do contexto e das condições de possibilidades estabelecidas na organização e ao assumir esse recorte, consideramos também campos e agentes paralelos, como o campo político e a força sindical.

A empresa vista como um campo nos permitiu considerar as práticas dos agentes e organizar nossas análises de modo que pudéssemos compreender as condições materiais de produção simbólica no âmbito dos discursos envolvendo a GP. E foi nesse sentido que percebemos que os discursos que visavam delinear as práticas no ambiente organizacional acabavam por não dar conta das capacidades inventivas e subversivas dos agentes, cujos habitus, adquiridos em outros campos e reforçados ou reelaborados no campo em questão, davam o tônus necessário ao processo de resistência à tentativa de dominação dissimulada sob o discurso da GP.

Em um trecho de um discurso registrado e arquivado pelo setor de comunicação da empresa no ano de 1965, pudemos notar essa investida na fala do então presidente da organização, no dia $1^{\circ}$ de maio deste mesmo ano, durante a inauguração do setor de laminação da siderúrgica:

Tudo isto foi vencido graças à significação extraordinária deste empreendimento, capaz de empolgar dois povos antípodas e despertar em cada um, japonês ou brasileiro, participante ou estranho, autoridade ou homem comum, diretores, técnicos, funcionários ou simples operários, o mais decidido empenho de colaboração e ajuda, o mais caloroso entusiasmo. Tudo isto foi vencido porque a [Empresa S.] não se fez apenas com frieza e técnica, mas sobretudo, com fé e coração ("FUNDADOR"..., 1966).

A fala do presidente recorre a termos apelativos, com conotações emocionais e segregadoras, embora a aparente proposta esteja vinculada à ideia de unificação. 
Ao usar verbos como vencer, empolgar e despertar, o agente da fala busca motivar e dar a noção de inclusão e reconhecimento aos funcionários da empresa. Os substantivos autoridade, empenho, colaboração, ajuda e entusiasmo, têm como precedente o termo decidido, dando o sentido de participação mútua e colaboração espontânea. As classificações e segregações presentes nas expressões japoneses ou brasileiros, autoridade ou homem comum, diretores, técnicos ou simples operários, frieza e técnica e fé e coração, parecem cooptar elementos aparentemente contraditórios no mesmo núcleo intencional da ação, onde a ideia de unificar é facilmente desconstruída ao se estabelecerem limites e diferenças, entre um agente e outro, ou entre uma ação e outra. Ao coadunar japoneses ou brasileiros, autoridade ou homem comum, por exemplo, há uma clara distinção e disposição entre ambos. Interessante observar que todas as afirmações estão relacionadas a um núcleo de poder, que se reafirma ao tentar negá-lo.

Esse discurso, ainda que pautado nas diferenças, tem a intenção de agregar diferentes agentes ou posições sob um único propósito. Como trazem Souza e Fenili (2016), tratase de uma ação que reveste o que se sabe ou se pensa sobre a cultura, de um viés claramente político, usado de forma instrumental, ainda que não assumida e muito menos declarada, para delinear ou reafirmar o poder entre as classes. No caso específico da fala apresentada acima, notase entre outras, a distinção acentuada ao lermos a expressão "simples operários". Isso corrobora com a afirmação de Bourdieu (2009a) de que é por meio do estabelecimento e reforço de ideais dominantes que a classe que detém mais capitais atua para integrar-se como classe dominante, ao mesmo tempo em que desestabiliza as classes dominadas por meio de um discurso "agregador", cujo objetivo submerso é a reafirmação da distinção. No trecho citado, as palavras do fundador, indicando a união que venceu as diferenças em nome do empreendimento, demonstra a afirmativa de Bourdieu (2009a) de que a mesma cultura que une, é a que separa, legitimando distinções, empurrando todas as culturas a ordenarem-se e situarem-se pela distância em relação ao grupo que detém mais poder.

Notem que na fala do presidente há espaços para a aceitação do discurso participativo como para o reconhecimento dos verdadeiros interesses de organização e controle que perpassam a adoção da GP. Nenhum desses elementos está oculto, contudo, eles demarcam limites que não são superados por quaisquer que sejam as ações de coadunação de interesses. Isso se evidencia ainda mais na fala de um superintendente de engenharia, profissional aposentado, que ao ser entrevistado, revela algumas contradições:
A administração japonesa era muito centralizadora e como eles ainda tinham resquícios militares muito fortes, eles tinham um sistema de hierarquia muito forte, porém um trabalho de equipe muito acentuado. Isso foi muito bem aceito pelos mineiros. [...] causou grandes benefícios na empresa, pois havia um esforço tecnológico coletivo e superação de dificuldades operacionais, refletindo também no relacionamento com os sindicatos e com os funcionários de modo geral (Entrevistado 1)

A interpretação do Entrevistado 1 reforça a reflexão proposta por Bourdieu (2009a) sobre a cultura ser o ponto de partida para os esquemas de interpretação dos agentes, que influencia suas crenças e condutas, dando sentido às relações de poder, na maioria das vezes impostas, mas suficientes para legitimar a ordem vigente. Na mesma fala percebe-se o confronto e a acomodação de diferenças culturais e representações de mundo, tornando fluidas a distinção social, em que a representação não é mais estrutural, mas situa-se nas pessoas, nos discursos, na universalidade das relações de poder e, ao mesmo tempo, na especificidade da demanda de cada grupo. Embora pareça ambíguo, esse é o ponto para a acomodação, para a reprodução homogênea de crenças, valores e divisões da sociedade, conforme o referencial colocado como a melhor opção para que a meta objetivada seja alcançada.

Ao apontar as principais características da gestão japonesa, tentando relacioná-las a aspectos nada coerentes com as disposições adquiridas e o habitus dos gestores orientais, organiza-se um discurso quase esquizofrênico, na tentativa de dissimular a diferença e a contradição. Essa característica também pode ser observada na fala desse superintendente, outrora engenheiro e coordenador de área, que o tempo todo recorre a palavras excludentes, para ainda assim, tentar defender a ideia de participação:

Não adianta você querer participar, se você não tem o conhecimento. E na engenharia, se você tem o conhecimento, o processo fica altamente democrático. Ele tem liberdade de participar, mas para quem é um leigo, como um engenheiro pouco conhecedor de determinado assunto, nem vai ouvir mesmo. [...] isso nós estamos falando sobre os aspectos técnicos. Agora, com os aspectos 
gerenciais, geralmente já vinha esse processo discutido no RH, com a participação somente da alta administração, uma vez decidido lá, que era participativo também, já que eram pessoas realmente entendidas de $\mathrm{RH}$, então uma vez estabelecida uma norma e aceita pela alta administração, era para aplicar e seguir (Entrevistado 1).

Tanto na fala do Entrevistado 1, quanto no discurso do fundador, percebe-se a valorização de um sistema de práticas legitimadas pela permanência no campo (no caso dos negócios e da cultura japonesa pautada na disciplina). Nota-se que há o distanciamento ao mesmo tempo em que se denota uma admiração pela cultura entendida como diferente, e assim, sem determinismo, adaptam-se as práticas sem a necessidade de clarificar os fins especificamente, embora inculcando os objetivos que devem ser comuns e o melhor caminho a ser percorrido. Nesse sentido, Bourdieu (2008b) nos traz a explicação de que é a relação mútua entre as experiências passadas e o habitus, que possibilitam a adesão, sem grandes questionamentos, ao modelo dominante.

No primeiro trecho da fala do Entrevistado 1, também pode ser notada a importância que a história que constitui a cultura possui para que o habitus se reifique em novos campos. A percepção que ele e outros funcionários tinham sobre a eficiência e a disciplina japonesa era respeitada e entendida como o melhor caminho, a melhor forma de se fazer, o que estava demonstrado na história que se sabia sobre os japoneses, a influência do militarismo e os resultados constantes ao longo do tempo. Esse habitus japonês trazido para o cenário organizacional foi historicamente constituído a partir de outros campos, cujos resultados das experiências garantiram a adesão do grupo em questão, não sendo necessária a força para o estabelecimento de uma ordem reificadora dos posicionamentos nesse campo.

Contudo, embora o discurso da GP tenha agregado em termos funcionais para a organização, pudemos observar a conscientização de alguns agentes sobre a adoção por trás da adoção do estilo japonês:

Foi uma herança [dos japoneses]. Ficou a marca. [...] O estilo continuou, com algumas adaptações. [...] Mudaram os critérios, por exemplo, eles tinham uma submissão muito grande, enquanto o brasileiro não aceita isso. Então ficou um sistema de trabalho em equipe, porém mais democrático (Entrevistado 1).

Conquanto tenha havido a reprodução da estrutura japonesa e o impacto da GP tenha alcançado êxito quanto aos discursos e as ações, os agentes não se eximiram completamente da capacidade crítica ou analítica.Isso ocorre porque os agentes são dotados de criatividade, e, em alguma medida, podem, em vez de reproduzir, subverter (BOURDIEU, 2008a, 2009a). E mesmo que isso não seja suficiente para a modificação da estrutura imposta, ocasiona pequenas revoluções. Esse é o cenário em que se estabelece a ilusão de obediência, no qual sobrevive algum grau de subjetividade.

Esses discursos de acomodação das regras do jogo, mostram que o agente pode dar um pouco de si à prática, numa relação doxica, onde dominação e resistência se complementam. A fala de um chefe de departamento aposentado também nos remete a essa ideia:

[...] os presidentes e os diretores sempre venderam essa imagem de que o ser humano era a parte mais importante da empresa e que você era parte integrante das decisões. Você poderia discordar de alguma decisão, mas você via sempre que se chegaria a um resultado (Entrevistado 3).

A coexistência entre disciplina/hierarquia e GP é característica do senso-consenso descrito como doxa, isto é, aquela dissimulação viabilizadora das relações de dominação (BOURDIEU, 2009a). Um acordo implícito que estimula os agentes à concorrência ou à colaboração, viabilizando uma espécie de naturalização das forças, coordenadas a partir de interesses específicos, que nem sempre convergem, mas se tocam suficientemente para serem acomodados no campo (BOURDIEU, 2009a).

A divisão que ao mesmo tempo faz convergir fica evidente na fala de um chefe de divisão que continua na ativa:

[...] o meu alicerce era tecnológico, então você conversa com quem sabe e não com o chefe. Eram engenheiros especialistas, mas eu lidava com operários também, eu transitava bem entre eles. O trabalho sempre 
foi em equipe e tinha os staffs de apoio (Entrevistado 4).

A mesma perspectiva, que projeta na capacidade técnica uma espécie de legitimação e ao mesmo tempo negação da hierarquia é encontrada na fala de um gerente da área de recursos humanos, segundo o qual, na organização em questão, "a hierarquia sempre foi baseada em quem tem a expertise no assunto" (Entrevistado 5). Nota-se aqui uma justificativa para a hierarquização das funções, numa tentativa de desvincular as posições das relações de poder. Para Bourdieu (2009a) isso ocorre de acordo com os capitais disponíveis no campo, ou seja, as relações de poder serão pautadas de acordo com a distribuição dos agentes segundo o capital de que dispõem. É o jogo praticado no campo que orienta a valorização dos capitais, nesse caso os títulos e o suposto conhecimento técnico que eles representam.

Como acontece em todos os campos, os capitais e os habitus adquiridos pelos agentes que atuam nesse campo são originados em outros campos, como o escolar e o cultural. O aproveitamento desses capitais na Empresa S. é o que acentua a valorização de saberes pressupostos, valorizados conforme os interesses em jogo, entendidos aqui como o processo de cooptação de adeptos que contribuam com o alcance dos interesses da organização.

O senso-consenso que perpassa o comportamento dóxico também perpassa as relações sindicais que envolvem as questões trabalhistas na Empresa S., o que pode ser evidenciado nas falas de um chefe de divisão e de um analista de recursos humanos:

Não vou dizer que o sindicato lá foi sempre manobrado, mas que é possível negociar com eles, mesmo a empresa mandando tantos funcionários embora. $\mathrm{O}$ pessoal do sindicato era inteligente de nunca entrar em conflito com a empresa e se prejudicarem. A própria empresa sabia o que poderia fornecer [...] Pede isso, isso e isso e anota mais isso aqui que a empresa pode fornecer e vocês colocam como se fosse reivindicação de vocês. [...] Se alguém quisesse fazer política lá dentro era cortado (Entrevistado 6).

Hoje em dia não adianta fazer pressão mais no funcionário. [...] A última assembleia [de trabalhadores] foi por escrutínio secreto.
Acabou aquela coisa de levantar a mão. [... ] antigamente [os chefes] viam [a votação]. A ditadura tava aí ainda. O modelo de gestão do Brasil inteiro era esse, autoritário. Normalmente não era eleição, era aprovação da proposta na assembleia. Agora é tudo por votação secreta, até na mudança de turno (Entrevistado 7).

As relações objetivas e as permutas manifestadas na estrutura estão claramente presentes nas falas citadas acima, emitidas por agentes que também estão hierarquizados, mas que influenciam o campo a partir de sua posição em relação aos demais. Como aponta Bourdieu (2004), quando mais próximo o agente estiver do núcleo do poder, mais ele conhece os demais agentes e sua capacidade de barganha. Importante notar aqui, que a vontade de um indivíduo não é primordial para o alcance de certos objetivos. As vontades têm que ser adequadas aos recursos passíveis de serem barganhados. No caso da relação entre o sindicato e a Empresa S., observa-se uma coalizão que garante o seguir do jogo. Os ganhos possibilitados pelo sindicato, só contribuem para a doxa porque, em alguma medida, todos os agentes ganham alguma coisa, ainda que esses ganhos estejam de acordo, prioritariamente, com os interesses dos mais poderosos no campo.

O sindicato que deveria representar os interesses dos agentes menos favorecidos no campo, acaba se relacionando com a empresa de forma convergente, amenizando as lutas e dissimulando as práticas e estratégias de dominação. Observa-se nesse aspecto, a presença do que Bourdieu (2009c) apontou como a tendência das práticas se tornarem estratégias ambíguas, interessadas e desinteressadas, unilaterais e redutoras, mesmo quando permitem alguma luta, é possível que a própria luta, faça parte das regras do jogo. Nesse sentido, temos a fala de um analista de recursos humanos, segundo o qual "[...] a última greve que teve foi em 1964. Nunca mais se conseguiu fazer uma greve [...], porque os empregados sempre acreditaram na empresa e a empresa junto com o sindicato sempre buscou o melhor pelo funcionário" (Entrevistado 7).

As práticas intermediadas pelo sindicato, simbólicas ou não, também pretenderam tomar posição nos limites do campo aqui investigado, contribuindo assim para o estabelecimento da diferença e do controle, a partir da illusio, de não existir dominação, e da doxa, dissimulando negociações para possibilitar a própria dominação, incutindo nos agentes a colaboração e a naturalização das forças. $\mathrm{Na}$ fala do presidente do sindicato, temos indicativos desse processo: 
Eu participei de todas as administrações anteriores [...]. Homens que souberam respeitar a cultura da empresa acertaram $80 \%$ e erraram $20 \%$. [...] existiam os conflitos, alguns sindicais, mas nós conseguimos construir juntos um caminho. [...] Quarenta mil homens, não tem jeito, tem que ter disciplina. Às vezes interferia na vida pessoal da pessoa, na vida política, de partido [...] a pessoa era perseguida [...] mas não era muito não (Entrevistado 8).

Observem que o processo de dominação é resultante da história incorporada e objetivada pelos agentes da empresa, cujos habitus foram fortalecidos pelos capitais adquiridos, que deram o suporte necessário para que os agentes se acomodassem sob a pressão da estrutura, conforme sua posição hierárquica, orientando-os para a mudança ou estagnação, conforme os sistemas de possibilidades na empresa. Como nas palavras do Entrevistado 8, caso não se enquadrasse, "a pessoa era perseguida, mas não era muito não". A perseguição, assim, dependia do senso que o agente tinha do jogo. Se tivesse disciplina e fosse capaz de perceber as regras imbricadas nas relações entre as posições e escolhas possíveis, bem como os limites políticos e de trabalho, os agentes não teriam problemas significativos. Assim, instituiu-se o nomos, incutido a partir das crenças na disciplina e na hierarquia:

A comunicação é feita toda sexta-feira [...] o chefe da usina faz uma reunião com todos os gerentes de primeira linha [...] onde é tratado de tudo. [...] cada departamento faz com seus setores, chefe de seção, especialistas, chefe de divisão e técnicos. O chefe de seção passa pro supervisor na segunda feira e daí por diante, até operadores (Entrevistado 4).

Um gestor que ocupou uma das mais altas posições na Empresa S. aponta que apesar da hierarquia, o relacionamento entre a empresa e o sindicato oscilou entre a subserviência e a oposição fanática. Mas nos registros da empresa, percebemos que o que ele define como posição fanática foi um movimento ocorrido após o processo de redemocratização, que seguiu por anos. Conforme esse gestor, restava aos empregados resistir e perder o emprego, ou se aliar à empresa:
No sindicato oscilava entre subserviência e oposição fanática. [...] um técnico da Empresa S. [...] se levantou [...] fazia discursos e se aliou ao sindicato [...] perdeu o emprego [...] se candidatou a deputado e ganhou com voto massacrante da empresa. (Entrevistado 3)

Contudo, o componente ora subversivo e ocasionador da quebra de vínculo, ao ser valorizado em outros campos, torna o agente detentor de outras formas de capital, o que viabiliza seu retorno ao campo:

[...] Posteriormente ele foi cooptado pela própria empresa (risos). Ele deixou de ser um opositor ferrenho para ser um amigo da diretoria. O relacionamento entre o sindicato e a empresa sempre foi de perde e ganha (Entrevistado 3).

Esse aspecto demonstra a permeabilidade de um campo em relação a outros campos. Como aponta Bourdieu (2008b), o habitus de classe ou de grupo, viabiliza ou impossibilita o acesso a novas classes ou posições. Nesse sentido, o acesso de um agente a outras camadas a estrutura dependerá do uso que faz dos capitais que lhes são acessíveis. Assim, embora exista uma relação entre o habitus individual e o de classe, é o uso que o agente fará desses capitais que o permitirá ou não transitar na estrutura do campo. O caso do funcionário despedido e recontratado mostra como o babitus de classe o colocou em condição de lutar e, mesmo sendo demitido num primeiro momento, ao usar seus capitais em outro campo, alcançou êxito tal que se tornou desejável para o campo anterior, do qual havia sido expulso, sem de fato, ser dele completamente desvinculado. Para tanto, foram necessários esquemas de percepção, de concepção e de ação, nos quais o babitus individual pode ser considerado singularmente variante em relação ao habitus coletivo,

Como apontam Souza e Fenili (2016), o babitus de uma organização se molda a partir de sua história, de suas experiências compartilhadas a partir da história contada ao longo dos anos. Nesse sentido, desde o primeiro discurso analisado, nota-se a preponderância do discurso pautado na tradição, seja quando se recorre à tradição japonesa quanto à disciplina, seja na tradição da organização local quanto à obediência às regras organizacionais. A partir das incorporações dos agentes e da reelaboração da disciplina 
japonesa, é aberto o espaço para outras formas de subversão, pautadas no capital simbólico da competência técnica a fim de negar outras fontes de poder.

Assim, a disciplina japonesa mencionada pelos agentes legitima-se na qualificação técnica, predominante na área da engenharia e efetiva-se para a adoção de um ethos pautado no comprometimento técnico, no comportamento hierarquizado a partir de um saber admitido pela maior parte dos agentes. A adoção de práticas de GP e o discurso do trabalho em equipe, tornaram-se potencializadores do processo de submissão aos objetivos estabelecidos para a organização. Para que os instrumentos funcionassem de acordo com esses objetivos, e a maximização e melhoria do processo produtivo fossem alcançados, estabeleceuse um senso-consenso capaz de possibilitar decisões descentralizadas e, portanto, mais rápidas, sem contudo viabilizar ações subversivas em demasia, evitando, portanto, perdas para a empresa.

O alto nível de risco operacional e as preocupações com o controle de pessoal pautaram o discurso da GP, justificando o reforço constante da importância da disciplina, de tal modo que as relações intermediadas ou delineadas pela proposta de participação, funcionavam como vias de mão dupla, embora viabilizasse maior possibilidade de permanência do que de subversão, mais concordância do que negação. As liberdades e participação não eram efetivas, e estavam restritas à formalidade técnica. Eram raras as possibilidades de subversão, embora elas estivessem ali. $\mathrm{Na}$ maioria das falas observamos a manutenção dos objetivos organizacionais, e apenas uma ou outra situação em que se pode subverter, ainda que momentaneamente a ordem vigente. O campo é permeável, dinâmico e inconstante. Ainda que previsível em sua essência, nem sempre o campo dispõe de todos os recursos ou agentes necessários para evitar os males coletivos que podem aplacar os interesses dos dominantes. Isso, contudo, apenas complica um pouco mais o processo, uma vez que ao incorporar os capitais de agentes ora entendidos como subversivos, existe a apropriação de capitais com o único intuito de se fortalecer perante outros campos.

\section{Considerações Finais}

A partir do objetivo proposto, foi possível compreender como as práticas de gestão participativa (GP) desenvolvidas na Empresa S. levaram à acomodação dos agentes e ao controle ou mesmo o cerceamento de comportamentos subversivos. Os agentes, dominados por um discurso inclusivo, têm suas práticas docilizadas não por força, mas pelo senso-consenso, pela illusio. Os agentes, assim, são cooptados a aderirem quase que espontaneamente às novas práticas organizacionais. Mesmo que às vezes surja o discurso de descontentamento, o próprio emissor desse discurso repensa sua inclusão e tende a voltar atrás em sua fala, avaliando que no final, aderir aos interesses da empresa tem algum aspecto que também lhe é positivo.

A codificação do campo em questão combinou efeitos econômicos e sociais, privilegiando os interesses da organização, mas dissimulando a preocupação com os interesses dos funcionários. Assim, algumas ficções foram estabelecidas, como no caso dos benefícios concedidos via sindicado que, na verdade, eram sinalizados antes pela própria empresa como viáveis. Isso vai ao encontro das afirmações de Bourdieu (2009b) de que as práticas estão imbricadas nas posições dos agentes, num espaço de forças e de lutas, nos quais as regras podem ser acomodadas ou subvertidas.

No caso dos benefícios citados, houve a acomodação das regras colocadas pela organização, mas no caso do funcionário que se opôs as regras, foi demitido, tornou-se político e voltou a ser contratado houve uma aparente subversão, que acabou sendo incorporada pela organização. Isso ocorre, por que de acordo com Bourdieu (2004), a partir das disposições adquiridas e do habitus, os agentes podem se reinventar e manter alguma autonomia, dependendo dos capitais distribuídos no campo, das regras estabelecidas para o jogo e da distância em relação ao núcleo de poder do campo.

Importante observar que a mesma estrutura que delimita as ações também proporciona resistências e incorporações/ adaptações, num processo que até pode ser conturbado num primeiro momento, mas é passível de acomodações e transições. Idas e vindas que requerem a prática dos agentes para alimentarem o campo, a partir das capacidades inventivas e dóxicas que singularizam a prática em função da estrutura necessária para cada campo. Notem que não estamos falando de estrutura em sentido estático, mas dinâmico, em que agentes comunicam o tempo todo seus interesses e necessidades de acomodação ou subversão. Para Bourdieu (2009a), isso ocorre porque as relações de poder perpassam um campo distribuem os agentes conforme os capitais valorizados no jogo. Capitais multiformes, que só têm valor para quem entende o jogo.

Nesse sentido, a GP permitiu que os agentes obtivessem ganhos de acordo com a distância que ocupavam em relação ao núcleo de poder, mas também de acordo com a habilidade em jogar o jogo. As conquistas dos agentes, sejam eles mais ou menos privilegiados na estrutura a partir 
de suas relações, não refletem necessariamente a satisfação pessoal ou individual, já que mesmo estas estão imbricadas na dinâmica do campo. Mas isso não representa a ausência de algum poder de decisão, apenas limita em certa medida o entusiasmo no sentido da subversão, como aponta Zibas (1997).

Lembremos, contudo, que os capitais e os habitus podem ser adquiridos pelos agentes em mais de um campo, simultaneamente, mas o aproveitamento dos capitais dependerá da recepção e valorização no campo onde serão utilizados. São os capitais que dão o suporte necessário para que cada agente reaja à pressão da estrutura, mas sem o entendimento das regras do jogo, dificilmente um agente consiga avançar na estrutura, ainda que disponha de algum capital (BOURDIEU, 2004).

A perspectiva bourdieana que não se prende exclusivamente ao pessimismo e muito menos ao otimismo. Nesse sentido, entendemos que sua grande contribuição é a de nos permitir uma visão mais abrangente, não imparcial, todavia, mas esclarecedora de alguns aspectos que não são tão facilmente enquadrados em modelos de gestão. No caso da GP, percebemos como o entendimento das regras do jogo pode tornar a vida dos agentes em condição de dominação mais ou menos confortável no campo. Isso não significa que não exista reflexão e que a passividade seja o elemento conciliador, pois os agentes em situação de dominação precisam elaborar estratégias mais rebuscadas para conciliar interesses e manter o fluxo dos objetivos organizacionais.

A luta pela permanência no campo e pela própria manutenção do campo requer esforços e estratégias de ambos os agentes, dominantes e dominados. As relações objetivas e as estratégias de manutenção ou subversão refletem as regras do jogo representando a luta pela permanência e avanço do campo. Não cabe ao analista pesquisador - definir se o agente que resiste é o que subverte ou o que acomoda, mas é importante compreender como as regras do jogo são incorporadas, elaboradas e devolvidas ao campo.

Como pôde ser observado nesta pesquisa, as forças originárias do tradicionalismo (japonês) e do grau de envolvimento em relação aos núcleos de poder (força sindical) foram elementos fundamentais para a acomodação dos interesses. Nesse sentido, compreendemos que a contribuição dessa pesquisa corre no sentido de percorrer as diferentes possibilidades de ação e de acomodação ou mobilização das forças. No mundo atual, ainda se faz necessária alguma articulação não tão óbvia, capaz de mobilizar em vez de impor. Isso requer maior flexibilidade e habilidade das organizações e significa alcançar comportamentos de docilidade tal que não seria possível por meio da força ou imposição. Para as organizações, fica a lição de que é preciso saber elaborar suas estratégias a fim de angariar adeptos aos interesses, para os trabalhadores, a ideia de que é mais salubre, às vezes, conhecer e jogar o jogo para talvez alcançar algum objetivo intrínseco.

\section{Referências}

BORDENAVE, J. E. D. O que é participação. São Paulo: Brasiliense, 1983.

BOURDIEU, P. Os usos sociais da ciência: por uma sociologia clínica do campo científico. São Paulo: UNESP, 2004.

A produção da crença. 3. ed. Porto Alegre: Zouk, 2008a.

Razões práticas: sobre a teoria da ação. 9. ed. Campinas: Papirus, 2008b.

A economia das trocas linguísticas. São Paulo: EDUSP, 2008c.

O poder simbólico. 12. ed. Rio de Janeiro: Bertrand Brasil, 2009a.

Coisas Ditas. São Paulo: Brasiliense, 2009b.

A economia das trocas simbólicas. 6. ed. São Paulo: Perspectiva, 2009c.

CARVALHO NETO, A. Relações de Trabalho e Gestão de Pessoas: entre o macro e o micro? Provocações epistemológicas. Rege, v. 19, n. 3, p. 299-308, 2012. doi: $10.5700 /$ rege464

DONADONE, J. C. A. Apropriação e Recontextualização de Práticas Organizacionais. RAE-eletrônica, v. 1, n. 1, p. 1-14, 2002. Disponível em: http://goo.gl/zQvjny. Acesso em 03 abr. 2016.

"FUNDADOR": a Empresa $S$ se fez com fé e coração. Jornal interno da Empresa S., Belo Horizonte, 1 jun. 1966.

EVERETT, J. Organizational research and praxeology of Pierre Bourdieu. Organizational Research Methods, v. 5, n. 1, 56-80, 2002. doi:10.1177/1094428102051005

FARIA, J.H. Gestão Participativa: relações de poder e de trabalho nas organizações. São Paulo: Atlas, 2009. 
FURTADO, R. A. Retomando o debate sobre Gestão Participativa nas empresas a partir da contribuição da Teoria da Estruturação. ENCONTRO NACIONAL DE PÓSGRADUAÇÃO E PESQUISA EM ADMINISTRAÇÃO, 32., 2008, Rio de Janeiro. Anais... Rio de Janeiro/RJ: ANPAD. Disponível em: http://goo.gl/dJMMrg. Acesso em 28 mar. 2016.

GIDDENS, A. A constituição da sociedade. São Paulo: Martins Fontes, 1989.

Gil, A.C. Gestão de Pessoas: enfoque nos papéis profissionais. São Paulo: Atlas, 2007.

GUimarÃES, V. N.; KOROSUE, A.; CORRÊAA, F. Z. M. Empreendimentos auto-geridos em Santa Catarina: uma alternativa democrática à produção. In: PICCININI, V. et al. (Orgs). O mosaico do trabalho na sociedade contemporânea: persistências e inovações. Porto Alegre: UFRGS, 2006.

HECKSCHER, C. C. The new unionism: employee involvement in the changing corporation. Ithaca: ILR Press, Cornell University Press, 1996.

KAUFMAN, B. E. The theory and practice of strategic HRM and participative management. Antecedents in early industrial relations. Human Resource Management Review, v. 11, p. 505-533, 2001. doi:10.1016/S10534822(01)00051-1

KOCHAN, T. A.; OSTERMAN, P. The mutual gains enterprise: Forging a winning partnership among labor, management and government. Boston: Harvard Business School Press, 1994.

KOZICK, K.; COELHO, S. R.; ALMEIDA, P. J. (2013). Apontamentos sobre o método empregado por Pierre Bourdieu nas Ciências Sociais e a sua repercussão no âmbito jurídico. Revista de Direitos Fundamentais e Democracia, v. 13, n. 13, p. 64-80, 2013. Disponível em: http://goo.gl/1j4hhy. Acesso em 28 mar. 2016.

LOCKE, R. M. O futuro das relações de trabalho e de emprego. In: CASTRO, A.B. O futuro da indústria no Brasil e no mundo: os desafios do século XXI. Rio de Janeiro: Campus, 1999.

MATTOS, P. C. L. Análise de entrevistas não estruturadas: da formalização à pragmática da linguagem. In: GODOI, C. K.; BANDEIRA-DE-MELO, R.; SILVA, A. B. (Orgs.). Pesquisa qualitativa em estudos organizacionais: paradigmas, estratégias e métodos. São Paulo: Saraiva, 2006.
MISOCZKY, M. C. A. Implicações do uso das formulações sobre campo de poder e ação de bourdieu nos estudos organizacionais. Rev. Adm. Contemp., v. 7, n. esp., p. 9-30, 2003. doi:10.1590/S1415-65552003000500002

NOGUEIRA, A. R. R. M.; BIZARRIA, F. P. A.; TASSIGNY, M. M. Gestão participativa no terceiro setor em organizações cearenses. Revista Pensamento Contemporâneo em Administração, v. 8, n. 4, p. 123139, 2014. doi:10.12712/rpca.v8i4.433

PARDO-DEL-VAL, M.; MARTÍNEZ-FUENTES, C.; ROIG-DOBÓN, S. Participative management and its influence on organizational change. Management Decision, v. 50, v. 10, p. 1843-1860, 2012. doi:10.1108/00251741211279639

PATRUS, R. et al. (2012). Complexidades da responsabilidade social empresarial no Brasil: terceirização e gestão participativa. Revista de Gestão Social e Ambiental, v. 6, n. 2, p. 45-59. doi:10.5773/rgsa.v6i2.309

PETERS, G. Habitus, reflexividade e neo-objetivismo na teoria da prática de Pierre Bourdieu. Rev. Bras. Ci. Soc., v. 28, n. 83, p. 47-71, 2013. doi:10.1590/S010269092013000300004

PIORE, M. J. The Future of Unions. In: STRAUSS, G.; GALlAGHER, D.G.; FIORITO, J. (Eds.). The State of the Unions. EUA: Industrial Relations Research Association, 1991.

RIVERA, A.; BRITO, M A pesquisa como prática social: um estudo sob a perspectiva bourdieusiana. Organ. Soc., v. 22 , n. 75 , p. 561-582, 2015. doi:10.1590/1984-9230755

SCARTEZINI, N. Introdução ao método de Pierre Bourdieu. Cadernos de Campo, v. 14/15, p. 25-37, 2011. Disponível em: http://goo.gl/SDjGOu. Acesso em 28 mar. 2016.

SILVEIRA, R. Z.; OLIVEIRA, F. Z.; PALASSI, M. P. Gestão participativa: panorama da publicação científica brasileira de 1997 a 2010. Gestão Contemporânea, v. 9, n. 12, p. 69-90, 2012. Disponível em: http://goo.gl/I3gKNY. Acesso em 22 mar. 2016.

SOUZA, E.C.L.; FENILI, R.R. O estudo da cultura organizacional por meio das práticas: uma proposta à luz do legado de Bourdieu. Cad. EBAPE.BR, v. 14, n. 4, p. 872-890, 2016. doi:10.1590/1679-395141183

SOUZA FILHO, O. V. et al. "Um arranjo produtivo em cheque": campo, habitus e capital simbólico em um Arranjo Produtivo Local moveleiro em Minas Gerais. Rev. Adm. 
(São Paulo), v. 48, n. 4, p. 671-687, 2013. doi:10.5700/ rausp1113

SWARTZ, D. L. Bringing Bourdieu's master concepts into organizational analyses. Theory and Society, v. 37, p. 4552, 2008. doi:10.1007/s11186-007-9053-x

TOLFO, S. R.; PICCININI, V. C.; GUIMARÃES, V. N. G. Trabalho, Inovação e Participação: Um Estudo Multicase em Empresas do Setor Metal-Mecânico do Rio Grande do Sul. In: ENCONTRO NACIONAL DE PÓSGRADUAÇÃO E PESQUISA EM ADMINISTRAÇÃO, 23., 1999, Foz do Iguaçu. Anais... Foz do Iguaçu/PR: ANPAD: Disponível em: http://goo.gl/tb85t9. Acesso em 28 mar. 2016.

TRAGTENBERG, M. Administração, poder e ideologia. São Paulo: Moraes, 1980.

THIRY-CHERQUES, H. R. Pierre Bourdieu: a teoria na prática. Rev. Adm. Pública, v. 40, n. 1, p. 27-55, 2006. doi:10.1590/S0034-76122006000100003

ZIBAS, D. M. L. O reverso da medalha: os limites da administração industrial participativa. In: CARLEIAL, L.; VALLE, R. (Orgs.). Reestruturação produtiva e mercado de trabalho no Brasil. São Paulo: HucitecAbet, 1997. p. 122-139. 